\title{
Potent Potassium-competitive Acid Blockers: A New Era for the Treatment of Acid-related Diseases
}

\author{
Tadayuki Oshima* and Hiroto Miwa \\ Division of Gastroenterology, Department of Internal Medicine, Hyogo College of Medicine, Nishinomiya, Hyogo, Japan
}

Conventional proton pump inhibitors (PPIs) are used as a first-line therapy to treat acid-related diseases worldwide. However, they have a number of limitations including slow onset of action, influence by cytochrome P450 polymorphisms, unsatisfactory effects at night, and instability in acidic conditions. Alternative formulations of conventional PPIs have been developed to overcome these problems; however, these drugs have only introduced small advantages for controlling acid secretion compared to conventional PPIs. Potassium-competitive acid blockers (P-CABs) were developed and have beneficial effects including rapid, long-lasting, and reversible inhibition of the gastric hydrogen potassium ATPase, the proton pump of the stomach. Vonoprazan was recently innovated as a novel, orally active P-CAB. It is currently indicated for the treatment of gastric and duodenal ulcers, reflux esophagitis, and prevention of lowdose aspirin- or nonsteroidal anti-inflammatory drug-related gastric and duodenal ulcer recurrence in Japan. Vonoprazan does not require enteric coating as it is acid-stable, and it can be taken without food because it is quickly absorbed. Vonoprazan accumulates in parietal cells under both acidic and neutral conditions. It does not require an acidic environment for activation, has long-term stability at the site of action, and has satisfactory safety and tolerability. Thus, vonoprazan may address the unmet medical need for the treatment of acid-related diseases.

(J Neurogastroenterol Motil 2018;24:334-344)

\section{Key Words}

Anti-inflammatory agents, non-steroidal; Esophagitis; $\mathrm{H}^{+}, \mathrm{K}^{+}$-exchanging ATPase; Helicobacter pylori; Potassium-competitive acid blocker

\section{Introduction}

Proton pump inhibitors (PPIs) have often been used for acidrelated diseases including gastroesophageal reflux disease (GERD), gastric and duodenal ulcers, non-steroidal anti-inflammatory drug (NSAID)-associated ulcers, and Helicobacter pylori eradication therapy. Conventional PPIs with a benzimidazole structure ir- reversibly inhibit hydrogen potassium $\left(\mathrm{H}^{+}, \mathrm{K}^{+}\right)$-ATPases, which produce acid in gastric parietal cells and more strongly block acid secretion compared to histamine $\mathrm{H} 2$ receptor antagonists. ${ }^{1-3} \mathrm{Al}-$ though PPIs have been used for more than a quarter-century as a first-line treatment for these diseases, it has become clear that there are some issues in need of improvement (Table 1). ${ }^{4}$ First, it takes several days to show maximal effect. ${ }^{5-7}$ Reflux symptoms of GERD are not sufficiently relieved after the first dose of PPIs in two-thirds

Received: January 22, 2018 Revised: April 3, 2018 Accepted: April 17, 2018

(a) This is an Open Access article distributed under the terms of the Creative Commons Attribution Non-Commercial License (http://creativecommons. org/licenses/by-nc/4.0) which permits unrestricted non-commercial use, distribution, and reproduction in any medium, provided the original work is properly cited.

${ }^{*}$ Correspondence: Tadayuki Oshima, MD, PhD

Division of Gastroenterology, Department of Internal Medicine, Hyogo College of Medicine 1-1 Mukogawa-cho, Nishinomiya, Hyogo 663-8501, Japan

Tel: +81-798-45-6662, Fax: +81-798-45-6661, E-mail: t-oshima@hyo-med.ac.jp 
Table 1. Comparison of Potassium-competitive Acid Blocker and Proton Pump Inhibitor

\begin{tabular}{|c|c|c|}
\hline & $\begin{array}{c}\text { P-CAB } \\
\text { (vonoprazan) }\end{array}$ & PPI \\
\hline 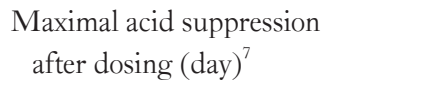 & 1 & $3-5$ \\
\hline $\begin{array}{l}\text { Influence of CYP2C19 } \\
\text { polymorphisms }^{10,11,34,45,46,48,49}\end{array}$ & - & + \\
\hline Influence of meal ${ }^{15,42}$ & - & + \\
\hline Stability in acidic conditions ${ }^{15}$ & \multicolumn{2}{|c|}{$>$} \\
\hline $\begin{array}{l}\text { Acid suppression at night } \\
(\mathrm{pH} 4 \mathrm{HTR})(\text { mean } \pm \mathrm{SD}, \%)^{48}\end{array}$ & \multicolumn{2}{|c|}{$\begin{array}{l}67.9 \pm 28.3 \text { vs } 12.9 \pm 10.9(\mathrm{E}) \\
84.3 \pm 20.3 \text { vs } 15.3 \pm 13.3(\mathrm{R})\end{array}$} \\
\hline $\begin{array}{l}\text { H. pylori eradication rate } \\
\text { (first-line triple therapy) }(\%)^{61}\end{array}$ & 92.6 & $75.9(\mathrm{~L})$ \\
\hline $\begin{array}{l}\text { Healing rate of sever reflux } \\
\text { esophagitis } \\
\left(\mathrm{LA}, \text { Grade C/D) }(\%)^{49,91}\right.\end{array}$ & $88.0-96.0$ & 53.9-82.6(L) \\
\hline PPI-refractory GERD ${ }^{92,93}$ & $=$ & \\
\hline
\end{tabular}

P-CAB, potassium-competitive acid blocker; PPI, proton pump inhibitor; HTR, holding time ratio; LA, Los Angeles; GERD, gastroesophageal reflux disease; CYP, cytochrome P450; E, esomeprazole; L, lansoprazole; R, rabeprazole; >, $\mathrm{P}-\mathrm{CAB}$ is better than $\mathrm{PPI}$.

of patients because of its slow onset of the action, ${ }^{8,9}$ and one-half of patients still have symptoms even after 3 days of treatment. ${ }^{9}$ Second, the effects of PPIs are influenced by cytochrome P450 (CYP) 2C19 polymorphism. ${ }^{10,11}$ Third, its effects at night are not satisfactory. ${ }^{12-14}$ Finally, although it requires an acidic environment for activation, PPIs are unstable in acidic conditions, ${ }^{15}$ so enteric coating is needed.

To overcome the aforementioned unmet needs, alternative formulations of conventional PPIs and new $\mathrm{H}^{+}, \mathrm{K}^{+}$-ATPase inhibitors have been established. With these efforts, vonoprazan (TAK-438), a potassium-competitive acid blocker (P-CAB), was developed. It was found to have satisfactory effects and a good safety profile in clinical studies of gastric and duodenal ulcers, reflux esophagitis, NSAID-associated ulcers, and $H$. pylori eradication. Vonoprazan (Takecab) was released to the market in Japan in February 2015. In this review, we summarize the effects of P-CABs, mainly using vonoprazan data.

\section{Alternative Formulation of Conventional Proton Pump Inhibitors}

Immediate-release omeprazole and dexlansoprazole modified release (MR), which improve nocturnal acid breakthrough (NAB), have been introduced as alternative formulations of PPIs in some countries. ${ }^{16,17}$ Dexlansoprazole MR is the R-enantiomer of lanso-

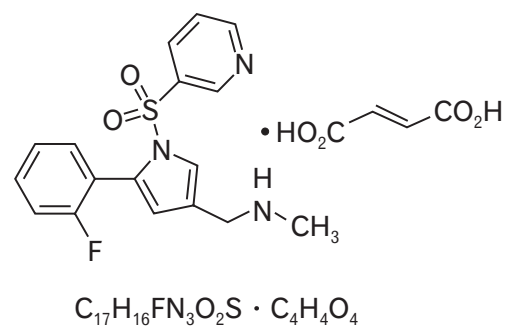

Figure 1. Chemical structure of vonoprazan.

prazole and is a PPI with dual delayed-release formulation. ${ }^{18}$ The dual release system in the duodenum and small intestine achieved 2 peak concentrations within 2 hours and 5 hours after administration. ${ }^{19}$ Percentage time 24-hour intragastric $\mathrm{pH}$ above 4 of dexlansoprazole MR $60 \mathrm{mg}$ and lansoprazole $30 \mathrm{mg}$ once daily for 5 days administration was $71 \%$ and $60 \%$, respectively $(P<0.01){ }^{20}$ However, these drugs only have small advantages for the control of acid secretion compared to conventional PPIs. ${ }^{20}$

\section{Development of Potassium-competitive Acid Blockers}

P-CABs were first developed in the $1980 \mathrm{~s}^{21}$ and have been studied by many pharmaceutical companies worldwide, as they rapidly, effectively, and reversibly inhibit the proton pump $\left(\mathrm{H}^{+}, \mathrm{K}^{+}\right.$ATPase $\alpha$ subunit). ${ }^{22}$ However, P-CABs such as the imidazopyridine compound SCH28080 from Schering-Plough Corporation have an imidazopyridine ring that correlated with hepatic toxicity in human clinical studies and did not show superior effects compared to conventional PPIs. Imidazopyridine derivatives including AR$\mathrm{H} 047108{ }^{23-25}$ and linaprazan (AZD0865), imidazonaphthyridine derivatives including soraprazan, ${ }^{26}$ pyrimidine derivatives including revaprazan (YH1885), and pyrrole derivatives including vonoprazan (TAK-438) (Fig. 1) were also developed. However, only revaprazan and vonoprazan are currently on the market (Table 2). A concentration of up to $75 \mathrm{mg}$ linaprazan provided similar efficacy to $40 \mathrm{mg}$ esomeprazole for the healing of reflux esophagitis and controlling of heartburn. ${ }^{27}$ However, linaprazan did not provide more clinical benefits than $20 \mathrm{mg}$ esomeprazole for the management of GERD. ${ }^{28}$ Because linaprazan had similar effects to esomeprazole but caused hepatic toxicity, its development was discontinued. Revaprazan is only available in South Korea and India, and is used for the treatment of peptic ulcers but not for GERD. Revaprazan rapidly inhibits gastric acid secretion but intragastric $\mathrm{pH}$ could only be increased to a maximum of 5 at the dosage used. ${ }^{29}$ The P-CAB YH4808 was developed in Korea; dosage $\geq 200 \mathrm{mg}$ produces a 
Table 2. Drugs in the Market and the Trials

\begin{tabular}{ll}
\hline \multicolumn{1}{c}{ Drug } & \multicolumn{1}{c}{ Phase } \\
\hline Revaprazan (YH1885) & Market (2007 South Korea, India) \\
Vonoprazan (TAK-438) & Market (2015 Japan) \\
& Phase III (Asia) \\
& Phase IIb (EU) \\
Tegoprazan (RQ-4) & Phase III (South Korea) \\
& Phase I (Japan) \\
YH4808 & Phase II (South Korea) \\
DWP14012 & Phase II (South Korea) \\
KFP-H008 & Preclinical (China) \\
\hline
\end{tabular}

rapid, sustained suppression of gastric secretion with good tolerability. ${ }^{30}$ The twice-daily use of YH4808 is more effective, especially at night, than the same dose used once-daily. ${ }^{30}$ However, this compound is still not available clinically. Other agents, DWP14012, and 1-(5-(1H-indol-5-yl)-1-(pyridin-3-ylsulfonyl)-1H-pyrrol-3-yl)-Nmethylmethanamine (KFP-H008), P-CABs, are under development. ${ }^{31,32}$ Tegoprazan is another potent $\mathrm{P}-\mathrm{CAB}^{33}$ that was successfully tested in a phase III trial in Korea and will be released to the market in 2018 (Table 2). A compound that has a pyrrole derivative in the center was found through high-throughput screening. ${ }^{34}$ After modifying the compound to reduce hepatic toxicity and influence of CYP2C19 polymorphism, vonoprazan was developed. ${ }^{35}$

\section{Vonoprazan}

\section{Pharmacokinetics}

Vonoprazan is a novel, orally active P-CAB that binds and inhibits $\mathrm{H}^{+}, \mathrm{K}^{+}$-ATPase at the final step in the acid secretory pathway in gastric parietal cells, and it has different mechanisms of action than conventional PPIs. It can inhibit the proton pump, even in neutral environments with an inhibitory constant $(\mathrm{Ki})$ of 10 $\mathrm{nM}$ at $\mathrm{pH} 7$ and of $3 \mathrm{nM}$ at $\mathrm{pH} 6.5 .^{36}$ It has stronger potential to inhibit the gastric proton pump than another P-CAB, SCH28080, and lansoprazole. The half-maximal inhibitory concentrations of vonoprazan, SCH28080, and lansoprazole were $0.018 \mathrm{nM}, 0.14$ $\mathrm{nM}$, and $7.6 \mu \mathrm{M}$, respectively. ${ }^{36}$ The half-life $\left(\mathrm{T}_{1 / 2}\right)$ of vonoprazan dissociation by potassium chloride was 12.5 hours in isolated proton pumps, and that of SCH28080 was less than 2 minutes. Therefore, vonoprazan has high affinity and slow clearance from gastric parietal cells, accumulating in both resting and stimulated conditions. ${ }^{37,38}$ The acid dissociation constant of vonoprazan is 9.37 , which is higher than that of conventional PPIs and other P-CABs. ${ }^{39}$

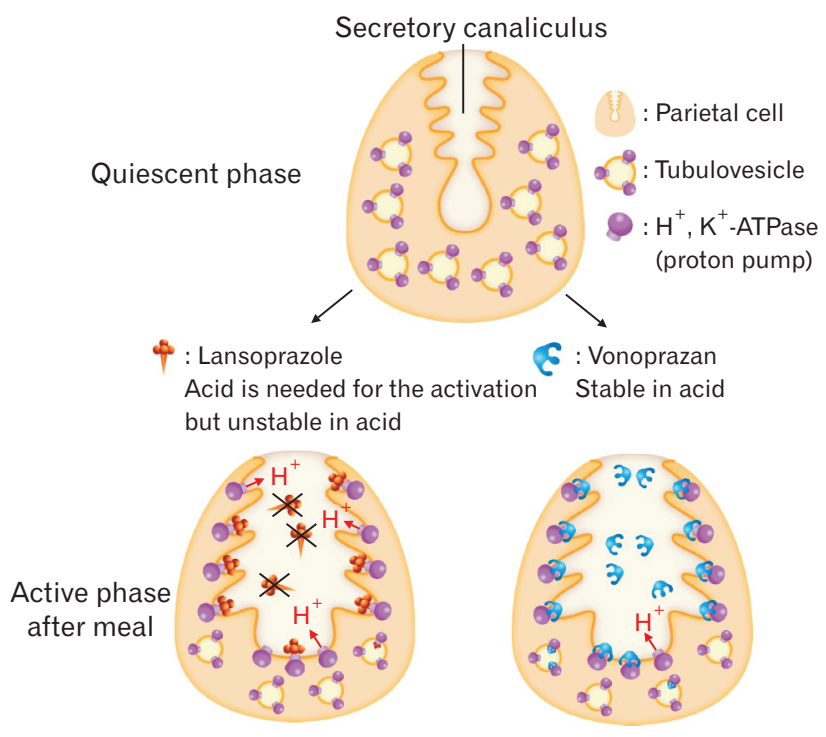

Figure 2. Comparison of mechanisms of action of lansoprazole (conventional proton pump inhibitor) and vonoprazan (potassium-competitive acid blocker). Hydrogen potassium $\left(\mathrm{H}^{+}, \mathrm{K}^{+}\right)$-ATPases are located in tubulovesicles in quiescent phase and appear on the apical membrane of secretory canaliculus in the active phase, which occurs after a meal. Lansoprazole converts to its active form in the secretory canaliculus, though it degrades soon after $(\mathrm{X})$. The active form of lansoprazole covalently binds to $\mathrm{H}^{+}, \mathrm{K}^{+}$-ATPase (proton pump). Vonoprazan stably accumulates in the acidic secretory canaliculus and noncovalently binds to $\mathrm{H}^{+}, \mathrm{K}^{+}$-ATPase with very a very slow dissociation rate and can inhibit newly exposed $\mathrm{H}^{+}, \mathrm{K}^{+}$-ATPase for a long time.

When vonoprazan is exposed to acidic conditions, it is instantly protonated and remains stable. It can accumulate, function, and bind the proton pump of gastric parietal cells in strongly acidic secretory canaliculi. Vonoprazan binds $-10 \AA$ from the ion binding site that is close to the middle of the membrane domain of $\mathrm{H}^{+}, \mathrm{K}^{+}$ATPase. Hydrogen bonding between Tyr799 and the sulfone of vonoprazan was suggested. ${ }^{36}$ The dissociation rate of vonoprazan from $\mathrm{H}^{+}, \mathrm{K}^{+}$-ATPase is slow and acid does not decomposed it. Non-ionic type of vonoprazan is decreased in a strong acidic secretory canaliculi and passive transport from the acidic secretory canaliculus to the cytoplasm is inhibited. It is therefore retained for a long time inside the parietal cells and can inhibit $\mathrm{H}^{+}, \mathrm{K}^{+}$-ATPase that is activated by further stimulation of acid secretion (Fig. 2). ${ }^{15,36,40}$ The concentration of vonoprazan is up to $10^{8}$-fold higher in the secretory canaliculus of the parietal cell than in the plasma. It can stay in the protonated form, and binds to the $\mathrm{H}^{+}, \mathrm{K}^{+}$-ATPase $\alpha$ subunit to compete with potassium binding, and inhibits the function of the pump. ${ }^{41}$ The binding of vonoprazan to the proton pump is ionic, and its effects are reversible and dose-dependent. 
Conventional PPI is a form of prodrug, which must be protonated to become an active form. To achieve this protonation process, the PPI should be reached in parietal cells in which acid secretion must be activated after the meal. Considering the time taken for this process, 30 minutes before the meal is required. ${ }^{42}$ However, vonoprazan can be taken regardless of meal ingestion and the rate of absorption is not affected by meals. ${ }^{15}$ The absorption speed of vonoprazan is rapid, and the time taken to reach maximum concentration in plasma is less than 2 hours after oral administration. ${ }^{43}$ After absorption, the $T_{1 / 2}$ in plasma is approximately 2 hours for conventional PPIs, but up to 9 hours for vonoprazan. ${ }^{44}$ Therefore, vonoprazan stays in the blood longer and can block acid secretion continuously. ${ }^{45}$ The pharmacokinetics of vonoprazan are similar in Japanese and non-Japanese subjects. ${ }^{45,46}$

The CYP2C19 polymorphism influences the pharmacokinetics of conventional PPIs and affects interindividual variability in pharmacodynamics. ${ }^{47}$ However, because vonoprazan is not primarily metabolized by CYP2C19, ${ }^{44}$ the data from clinical studies on healthy volunteers and GERD patients showed limited influence by CYP2C19 polymorphisms. ${ }^{35,45,46,48,49}$ Furthermore, the effects of clarithromycin, a potent CYP3A4 inhibitor, on the pharmacokinetics of vonoprazan were evaluated and no significant pharmacokinetic interactions were observed. ${ }^{50}$

\section{Pharmacodynamics}

Vonoprazan is effectively absorbed and quickly accumulates in parietal cells. In contrast, conventional PPIs require 3 to 5 days to achieve maximal and steady-state inhibition of acid secretion. ${ }^{7,51}$ The effect is more pronounced after the first dose of vonoprazan compared to conventional PPIs; a single dose of $20 \mathrm{mg}$ vonoprazan can increase intragastric $\mathrm{pH}$ to nearly 7 in as little as 4 hours. ${ }^{46}$ This rapid onset of action is appropriate for the treatment of breakthrough GERD symptoms and for on-demand therapy. Furthermore, $\%$ time 24-hour intragastric $\mathrm{pH}$ above 4 of vonoprazan $20 \mathrm{mg}$ once daily for 4 days and 7 days was $82.9 \%$ and $85.2 \%$, respectively ${ }^{46}$ and the effect continues without intragastric $\mathrm{pH}$ dipping below 4 . The means of night-time $\mathrm{pH}$ above 4 after administration of vonoprazan $20 \mathrm{mg}$ on day 1 were higher than after administration of esomeprazole $20 \mathrm{mg}$ or rabeprazole $10 \mathrm{mg}$ (Table 1 ). ${ }^{48}$ Once this $\mathrm{pH}$ is maintained through daily administration, the pepsin produced by chief cells cannot be activated. Therefore, vonoprazan is a strong acid blocker that has rapid, stable, and long-lasting effects $35,46,48,52$ and these effects were stronger than conventional $\mathrm{PPI}^{35,41,45,48,52,53}$ and prototype P-CAB. ${ }^{41}$ Phase I studies of single ascending ${ }^{45}$ and multiple repeat doses $^{46}$ in Japan and the United Kingdom revealed that vonoprazan was well-tolerated at single doses of 1-120 mg and at repeat doses of 10-40 mg. ${ }^{54}$ The mean percentage of time that patients had a intragastric $\mathrm{pH}$ above 4 after multiple doses of $40 \mathrm{mg}$ vonoprazan was $85.3 \%$ and $100.0 \%$ during the day and $86.5 \%$ and $100.0 \%$ at night (21:00-9:00) on days 1 and 7 , respectively. ${ }^{46}$

\section{Clinical Indications}

\section{Helicobacter pylori Eradication Therapy}

$H$. pylori infection can be eradicated by elevating intragastric $\mathrm{pH}$ using an acid suppressant in combination with at least 2 antibiotics. H. pylori enters the growth phase from a stationary phase at intragastric $\mathrm{pH}$ above 5, at which point it becomes susceptible to antibiotics. ${ }^{55,56}$ Although conventional PPIs have been used to suppress gastric acid secretion, recent $H$. pylori eradication rates have decreased due to increases in antibiotic-resistant $H$. pylori strains. ${ }^{57}$ Increasing the dosage of PPIs and changing antibiotics have been attempted to increase the eradication rate. ${ }^{58}$ In addition, the development of P-CABs that can strongly suppress acid secretion has been an attractive option for increasing the eradication rate. A randomized, double-blind study was conducted to prove the non-inferiority of $20 \mathrm{mg}$ vonoprazan compared to $30 \mathrm{mg}$ lansoprazole for the first-line triple therapy for $H$. pylori eradication with $750 \mathrm{mg}$ amoxicillin and $200 \mathrm{mg}$ or $400 \mathrm{mg}$ clarithromycin. ${ }^{59}$ Patients who did not achieve eradication also received second-line vonoprazan-based triple therapy with $750 \mathrm{mg}$ amoxicillin and 250 mg metronidazole..$^{59}$ All drugs were administered orally twice daily for 7 days. The eradication rate with vonoprazan was $92.6 \%$ compared to $75.9 \%$ with lansoprazole..$^{59}$ Both first-line and second-line therapies were satisfactory and non-inferiority was proven. ${ }^{59} \mathrm{~A}$ recent meta-analysis also showed the superiority of vonoprazan-based triple therapy compared to conventional PPI-based triple therapy. ${ }^{60}$ Therefore, vonoprazan-based triple therapy should be the first-line treatment for $H$. pylori eradication (Table 1). ${ }^{61}$

Both prospective and retrospective studies have shown that the $H$. pylori eradication rate with vonoprazan-based triple therapy for clarithromycin-resistant subgroup was significantly higher than that with PPI-based triple therapy. Two prospective randomized controlled studies showed no difference in the eradication rate between vonoprazan-based and PPI-based triple therapies in clarithromycinsensitive subgroup (Fig. 3)..$^{59,62}$ However, two retrospective studies indicated a superior eradication rate with vonoprazan-based triple therapy. ${ }^{63,64}$ These data indicate that the increased eradication rate with vonoprazan-based therapy is mainly gained in clarithromycin- 


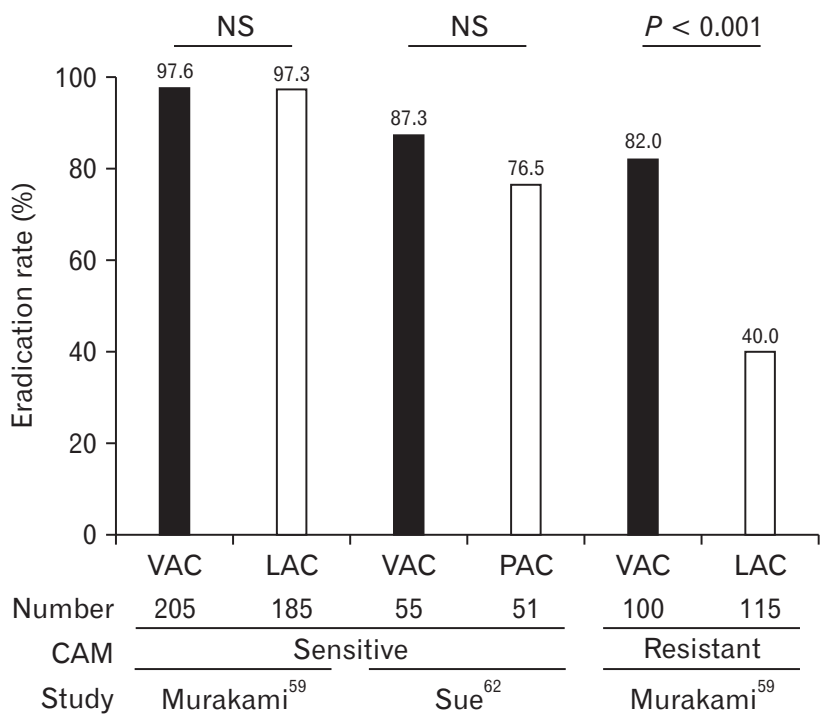

Figure 3. Eradication rate of Helicobacter pylori with vonoprazan and proton pump inhibitor (PPI). The $H$. pylori eradication rates by first-line triple therapies from randomized controlled trials are separately shown in clarithromycin (CAM)-sensitive and CAM-resistant subgroups. NS, not significant; VAC, vonoprazan + amoxicillin + clarithromycin; LAC, lansoprazole + amoxicillin + clarithromycin; PAC; PPI (lansoprazole, rabeprazole, or esomeprazole) + amoxicillin + clarithromycin.

resistant patients; thus, vonoprazan-based therapy must be effective for the clarithromycin-resistant $H$. pylori eradication, though sensitivity assay of clarithromycin of $H$. pylori is not recommended and is not included for reimbursement by Japan's national health insurance system. ${ }^{65}$ Alternatively, when acid secretion can be effectively and strongly suppressed by vonoprazan, clarithromycin may not be needed for $H$. pylori eradication therapy. The dual therapy of amoxicillin and high-dose PPI or poor metabolizer of CYP2C19 that can maintain the intragastric $\mathrm{pH}$ above 6 leads to a high $H$. $p y$ lori eradication rate, because increasing the $\mathrm{pH}$ to 6 or 7 allows the bacteria to enter the replicative state where they become susceptible to amoxicillin. ${ }^{57,66,67}$ Strong acid suppressive effect from the first dosage and even at night by vonoprazan may lead to a high $H$. pylori eradication rate. To prove this theory, a clinical study is ongoing in Japan (UMIN000022963). ${ }^{68}$

The eradication rate with vonoprazan-based triple therapy was also better than PPI-based triple therapy in young and middle age groups, indicating that strong acid inhibition is more effective in young than in old patients who may have less acid secretion with severe atrophic changes in gastric mucosa. ${ }^{69}$ The effects of vonoprazan for the second-line treatment of $H$. pylori eradication are not well known. A meta-analysis of second-line triple therapy did not show a difference between vonoprazan and conventional PPIs. ${ }^{60}$ As these data were obtained from retrospective studies, confounding factors might have existed that affected these results. In a single arm vonoprazan-based second-line triple therapy with amoxicillin and metronidazole in patients who failed vonoprazan- and lansoprazolebased first-line triple therapy, the eradication rate was as high as 98\%. ${ }^{59}$ Furthermore, vonoprazan-based triple therapies with amoxicillin and clarithromycin or with amoxicillin and metronidazole were safe and well-tolerated. ${ }^{70-72}$ Another study showed that vonoprazan-based first-line therapy with amoxicillin and clarithromycin was effective in $70.2 \%$ of patients who failed rabeprazole first-line triple therapy with amoxicillin and clarithromycin in Japan. ${ }^{73}$ There was even a case successfully treated with fourth-line vonoprazanbased triple therapy with amoxicillin and clarithromycin. ${ }^{74}$ These data indicate that the fast onset of increase and sustained increase in intragastric $\mathrm{pH}$ are important factors for increasing the $H$. pylori eradication rate. In addition, the eradication rate was higher in subjects without NAB than in those with $\mathrm{NAB}^{75}$ Although there are few drug interactions, it should also be noted that vonoprazan treatment significantly decreased the value of the urea breath test (UBT). ${ }^{76}$ Therefore, when UBT is performed to examine $H$. pylori eradication, vonoprazan treatment should be stopped at least 2 weeks before the test. Although the mechanisms how vonoprazan decreases the value of UBT are not clear, previous data have shown that urease activity is strongly affected by intragastric $\mathrm{pH}$, particularly $\mathrm{pH}$ levels above 4-5.5..$^{77,78}$ Therefore, a rapid increase in intragastric $\mathrm{pH}$ in response to the early and strong acid inhibitory effect of vonoprazan may reduce urease activity. ${ }^{45,46}$

\section{Gastroesophageal Reflux Disease}

GERD is one of the most common esophageal diseases, characterized by symptoms of heartburn and acid regurgitation due to reflux of the stomach contents. The prevalence of GERD diagnosed by heartburn and/or acid regurgitation symptoms in East Asia is $2.5-7.8 \%{ }^{79,80}$ The impact of GERD on quality of life (QOL) is large, and GERD is a burden on healthcare systems. ${ }^{81,82}$ The major goals of treating erosive esophagitis are to relieve symptoms, heal erosions, and prevent complications. ${ }^{83}$ Although host factors might exist because not all patients have abnormal gastroesophageal reflux, gastric acid is the principle factor underlying the development of reflux esophagitis, and PPIs have been the gold standard for treatment in the clinical setting., ${ }^{3,84,85}$ Intragastric $\mathrm{pH}$ above 4 holding time has been used to show the effects of acid-suppressive drugs, because erosive esophagitis can be controlled and healed when this time is long. ${ }^{86}$ However, the degree of acid suppression by PPIs 
is not complete and no data have shown that a $\mathrm{pH}$ of 4 is enough to control reflux symptoms. Furthermore, approximately $80 \%$ of patients with frequent heartburn experience heartburn at night, and $29 \%$ of those are awakened by coughing or choking due to gastroesophageal reflux at night. ${ }^{87,88}$ Nighttime acid reflux with NAB influences sleep quality and daytime QOL. More than $30 \%$ of patients on PPIs due to reflux esophagitis with heartburn continuously experience nocturnal heartburn; ${ }^{89}$ therefore, this issue is one of the unmet clinical needs. More than $50 \%$ of symptomatic GERD patients taking PPIs are not satisfied with the treatment, and more than $20 \%$ of patients take PPIs twice daily or purchase medicines over the counter in addition to their prescribed medicine..$^{90}$

The safety and dose-response profiles of vonoprazan were evaluated in an 8-week phase II study. Patients with erosive esophagitis were treated at doses of 5, 10, 20, and $40 \mathrm{mg}$ once daily for 8 weeks and compared to those who were treated with $30 \mathrm{mg}$ lansoprazole once daily for 8 weeks. Vonoprazan was effective and noninferior to lansoprazole for curing erosive esophagitis. ${ }^{49}$ Although the study was designed to show the noninferiority of vonoprazan to lansoprazole, the healing rate of severe esophagitis (Los Angeles [LA] classification, Grades C/D) with $20 \mathrm{mg}$ vonoprazan was higher than that with $30 \mathrm{mg}$ lansoprazole at week 2 (96.0\% vs 82.6\%) (Fig. 4). In another phase II study, the noninferiority of $20 \mathrm{mg}$ vonoprazan compared to $30 \mathrm{mg}$ lansoprazole for treating erosive esophagitis was confirmed and the long-term efficacy of vonoprazan was evalu-

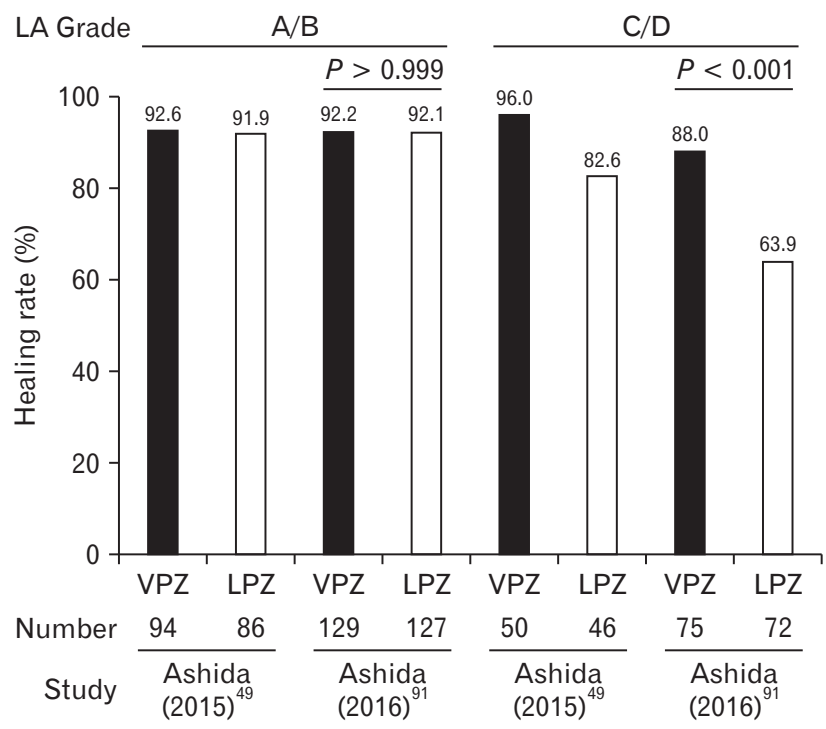

Figure 4. Healing rate of erosive esophagitis with vonoprazan (VPZ) and lansoprazole (LPZ) at week 2. Healing rates of erosive esophagitis with $20 \mathrm{mg} \mathrm{VPZ}$ and $30 \mathrm{mg} \mathrm{LPZ}$ at week 2 are separately shown in Los Angeles (LA) classification Grade A/B and C/D subgroups. ated. $^{91}$ In post hoc analyses, patients with severe esophagitis (LA Grades C/D) or with extensive CYP2C19 metabolism experienced better treatment effects in the vonoprazan group than in the lansoprazole group (Table 1). Long-term (52 weeks) maintenance treatment of $10 \mathrm{mg}$ or $20 \mathrm{mg}$ vonoprazan resulted in less than $10 \%$ erosive esophagitis recurrence and vonoprazan was well-tolerated overall. Vonoprazan was also assessed for the treatment of refractory GERD compared to conventional PPI. In an open label study, vonoprazan was effective for the treatment of PPI (standard singledose)-refractory symptomatic GERD (Table 1). ${ }^{92}$ Because this was an open label study, potential bias may have existed. However, the symptoms were quickly relieved in the study, and this effect might have correlated with the potent inhibition of acid production from the first dose of vonoprazan. Doses of $20 \mathrm{mg}$ and $40 \mathrm{mg}$ vonoprazan significantly inhibited gastric acid secretion after 24 hours and treated erosive esophagitis that was resistant to standard dose of conventional PPIs (Table 1). ${ }^{93}$ Further studies are warranted to prove the rapid relief of GERD symptoms by vonoprazan.

\section{Treatment of Gastric and Duodenal Ulcers}

Randomized, controlled trials confirmed the noninferiority of vonoprazan for the 8-week treatment of gastric ulcer $(93.5 \%$ and 93.8\% for vonoprazan and lansoprazole, respectively). ${ }^{94}$ However, the noninferiority of vonoprazan compared to lansoprazole for the 6-week treatment of duodenal ulcer was not confirmed in the trial (95.5\% and $98.3 \%$ for vonoprazan and lansoprazole, respectively). The factors that affected these data might have correlated with dropout subjects who did not complete the study and were counted as non-healed subjects. Some of the subjects might have stopped the study because their symptoms were quickly relieved by vonoprazan or lansoprazole. Further studies are needed to conclude the efficacy of vonoprazan for the treatment of gastric and duodenal ulcers.

\section{Prevention of Recurrence of Low-dose Aspirin/Non-steroidal Anti-inflammatory Drug-related Ulcers}

NSAIDs cause gastrointestinal (GI) ulcers and increase the risk of serious GI complications. ${ }^{95}$ Risk factors associated with the occurrence of NSAID-related ulcers are history of GI ulcer with bleeding, concomitant use of two or more NSAIDs/low-dose aspirin (LDA), high dose of NSAIDs, concomitant use of anticoagulant agent, history of gastric and duodenal ulcers, age over 70 years, and $H$. pylori infection. ${ }^{96-98}$ NSAID use and $H$. pylori infection are independent and synergistic risk factors for gastric and duodenal ulcers and bleeding. ${ }^{99}$ This is the most important point 
when considering NSAID-related gastric and duodenal ulcer and complications. Furthermore, not only NSAID and H. pylori infection but also host factors are involved in the development of ulcers. However, it is still not clear what definitive host factors are involved in the development of ulcers in $H$. pylori-infected patients and/ or NSAID users. Therefore, patients at risk should discontinue NSAID use. However, this is sometimes not easy or feasible, as the continuous use of NSAIDs can control pain and improve QOL in patients with chronic pain. ${ }^{100,101}$ LDA can also decrease the recurrence of cardiovascular and cerebrovascular diseases. In these cases, concomitant use of gastroprotective agents including PPI should be considered. $^{95}$

A meta-analysis showed that PPIs significantly reduced the risk of NSAID-associated ulcers compared to placebo, and NSAIDs plus PPI was the most cost-effective strategy for preventing upper GI ulcers in patients on long-term NSAID therapy. ${ }^{102}$ A dose of 20 mg esomeprazole once daily was effective and safe for preventing NSAID-associated upper GI ulcer recurrence. ${ }^{103}$ Because NSAIDassociated upper GI injury is pH-dependent, the higher the intragastric $\mathrm{pH}$, the lower the incidence of injury. ${ }^{104,105}$ Vonoprazan strongly inhibits acid production from the first dose. No clinically meaningful interactions during concomitant use of vonoprazan and NSAIDs were observed, and vonoprazan was well-tolerated when administered with LDA or NSAIDs. ${ }^{106}$ Therefore, the efficacy and safety of vonoprazan for preventing NSAID-associated upper GI ulcer recurrence has been evaluated in patients continuously receiving NSAIDs in double-blind, randomized trials. ${ }^{107}$ Vonoprazan (10 $\mathrm{mg}$ and $20 \mathrm{mg}$ ) was effective for NSAID-associated upper GI secondary ulcer prevention. These results were consistent with previous studies that investigated the effect of PPIs in NSAID-associated secondary ulcer prevention. ${ }^{103,108,109}$ No unexpected adverse events were identified during at least a 1-year period of exposure to vonoprazan. After these data were introduced, the Japanese government approved $10 \mathrm{mg}$ vonoprazan for the prevention of recurrent upper GI ulcers during long-term NSAID therapy.

The efficacy and safety of vonoprazan for preventing recurrent upper GI ulcer in patients with long-term LDA therapy was evaluated in a phase III study. ${ }^{110}$ The rate of gastric and duodenal ulcer recurrence after 24 weeks of LDA therapy was $2.8 \%$, and was $0.5 \%$ with $15 \mathrm{mg}$ lansoprazole or $10 \mathrm{mg}$ vonoprazan. Thus, $10 \mathrm{mg}$ vonoprazan is as effective as $15 \mathrm{mg}$ lansoprazole for preventing recurrent upper GI ulcer during LDA therapy. ${ }^{110}$ Vonoprazan treatment resulted in lower ulcer recurrence rates and upper GI bleeding compared to lansoprazole during long-term LDA treatment. Vonoprazan has long-term safety (at least 24 weeks) and is well-tolerated.

\section{Possible Complications of Potassium- competitive Acid Blockers}

The more acid that is secreted, the more that effective acid suppression is needed, and the more the effects of vonoprazan stand out. When vonoprazan is used for short-term acid suppression, there are no problematic side effects. However, when long-term acid suppression treatment is needed, side effects such as hypergastrinemia, pneumonia, small bowel bacterial overgrowth, and Clostridium difficile infection may occur. ${ }^{11-115}$ In clinical trials evaluating the safety and tolerability of vonoprazan for GERD ${ }^{91}$ and LDA/ NSAID-associated upper GI secondary ulcer prevention, ${ }^{107,110}$ the common treatment-emergent adverse events (TEAEs) irrespective of causal relationship to study medication with an incidence of $\geq 5 \%$ in vonoprazan $10 \mathrm{mg}$ and $20 \mathrm{mg}$ were nasopharyngitis, diarrhea, constipation, upper respiratory tract inflammation, fall, gastroenteritis, and eczema. Most TEAEs were classified as mild in intensity. To verify the long-term safety and efficacy of vonoprazan, a study evaluating the safety of 5-year maintenance therapy of $10 \mathrm{mg}$ or 20 $\mathrm{mg}$ vonoprazan in patients with healed erosive esophagitis is ongoing in Japan (NCT02679508). ${ }^{116}$

\section{Conclusions}

In conclusion, vonoprazan is superior to conventional PPIs for suppressing acid secretion, especially at night, and there was no difference in efficacy depending on CYP2C19 genotype status. In addition, vonoprazan was shown to overcome the weaknesses associated with conventional PPIs. The advantages of vonoprazan compared to previous P-CABs are that it does not have the hepatic toxicity observed with previous $\mathrm{P}-\mathrm{CABs}$, and it has slow dissociation from $\mathrm{H}^{+}, \mathrm{K}^{+}$-ATPase while its actions are long-lasting. In clinical trials, vonoprazan showed potent acid-suppressive effects, and rapid and long-lasting effects for the treatment of acid-related diseases including reflux esophagitis, LDA/NSAID-associated ulcer recurrence, and $H$. pylori infection. It also had satisfactory safety and tolerability after at least 1 year of treatment. Thus, vonoprazan may address the unmet medical need for the treatment of acid-related diseases.

Financial support: None.

Conflicts of interest: Tadayuki Oshima has received lecture fees from Takeda Pharmaceutical Co, Ltd and Otsuka Pharmaceutical Co, Ltd. Hiroto Miwa has received research grants and lecture 
fees from Takeda Pharmaceutical Co, Ltd and Otsuka Pharmaceutical Co, Ltd.

Author contributions: Tadayuki Oshima collected references, summarized data, analyzed data, and prepared manuscript; and Hiroto Miwa supervised and approved the manuscript.

\section{References}

1. Lindberg P, Brändstrom A, Wallmark B, Mattsson H, Rikner L, Hoffmann KJ. Omeprazole: the first proton pump inhibitor. Med Res Rev 1990;10:1-54.

2. Bell NJ, Burget D, Howden CW, Wilkinson J, Hunt RH. Appropriate acid suppression for the management of gastro-oesophageal reflux disease. Digestion 1992;51(suppl 1):59-67.

3. Chiba N, De Gara CJ, Wilkinson JM, Hunt RH. Speed of healing and symptom relief in grade II to IV gastroesophageal reflux disease: a metaanalysis. Gastroenterology 1997;112:1798-1810.

4. Ashida K. Notes on features and uses of medications used for PPIresistant GERD, drugs under development and future prospects. Jpn J Med Pharm Sci 2014;71:591-596.

5. Cederberg C, Lind T, Röhss K, Olbe L. Comparison of once-daily intravenous and oral omeprazole on pentagastrin-stimulated acid secretion in duodenal ulcer patients. Digestion 1992;53:171-178.

6. Dammann HG, Burkhardt F. Pantoprazole versus omeprazole: influence on meal-stimulated gastric acid secretion. Eur J Gastroenterol Hepatol 1999;11:1277-1282.

7. Andersson K, Carlsson E. Potassium-competitive acid blockade: a new therapeutic strategy in acid-related diseases. Pharmacol Ther 2005;108:294-307.

8. Bytzer P, Morocutti A, Kennerly P, Ravic M, Miller N. Effect of rabeprazole and omeprazole on the onset of gastro-oesophageal reflux disease symptom relief during the first seven days of treatment. Scand J Gastroenterol 2006;41:1132-1140.

9. Peura DA, Riff DS, Snoddy AM, Fennerty MB. Clinical trial: lansoprazole 15 or $30 \mathrm{mg}$ once daily vs. placebo for treatment of frequent nighttime heartburn in self-treating subjects. Aliment Pharmacol Ther 2009;30:459-468

10. Chong E, Ensom MH. Pharmacogenetics of the proton pump inhibitors: a systematic review. Pharmacotherapy 2003;23:460-471.

11. Furuta T, Shirai N, Sugimoto M, Nakamura A, Hishida A, Ishizaki T. Influence of CYP2C19 pharmacogenetic polymorphism on proton pump inhibitor-based therapies. Drug Metab Pharmacokinet 2005;20:153-167.

12. Katz PO, Castell DO, Chen Y, Andersson T, Sostek MB. Intragastric acid suppression and pharmacokinetics of twice-daily esomeprazole: a randomized, three-way crossover study. Aliment Pharmacol Ther 2004;20:399-406

13. Johnson DA, Katz PO. Nocturnal gastroesophageal reflux disease: issues, implications, and management strategies. Rev Gastroenterol Disord 2008;8:98-108
14. Sachs G, Shin JM, Hunt R. Novel approaches to inhibition of gastric acid secretion. Curr Gastroenterol Rep 2010;12:437-447.

15. Otake K, Sakurai Y, Nishida H, et al. Characteristics of the novel potassium-competitive acid blocker vonoprazan fumarate (TAK-438). Adv Ther 2016;33:1140-1157.

16. Castell D, Bagin R, Goldlust B, Major J, Hepburn B. Comparison of the effects of immediate-release omeprazole powder for oral suspension and pantoprazole delayed-release tablets on nocturnal acid breakthrough in patients with symptomatic gastro-oesophageal reflux disease. Aliment Pharmacol Ther 2005;21:1467-1474.

17. Katz PO, Koch FK, Ballard ED, et al. Comparison of the effects of immediate-release omeprazole oral suspension, delayed-release lansoprazole capsules and delayed-release esomeprazole capsules on nocturnal gastric acidity after bedtime dosing in patients with night-time GERD symptoms. Aliment Pharmacol Ther 2007;25:197-205.

18. Hershcovici T, Jha LK, Fass R. Dexlansoprazole MR: a review. Ann Med 2011;43:366-374

19. Vakily M, Zhang W, Wu J, Atkinson SN, Mulford D. Pharmacokinetics and pharmacodynamics of a known active PPI with a novel dual delayed release technology, dexlansoprazole MR: a combined analysis of randomized controlled clinical trials. Curr Med Res Opin 2009;25:627638.

20. Wittbrodt ET, Baum C, Peura DA. Delayed release dexlansoprazole in the treatment of GERD and erosive esophagitis. Clin Exp Gastroenterol 2009;2:117-128.

21. Beil W, Hackbarth I, Sewing KF. Mechanism of gastric antisecretory effect of SCH 28080. Br J Pharmacol 1986;88:19-23.

22. Wurst W, Hartmann M. Current status of acid pump antagonists (reversible PPIs). Yale J Biol Med 1996;69:233-243.

23. Berg AL, Böttcher G, Andersson K, et al. Early stellate cell activation and veno-occlusive-disease (VOD)-like hepatotoxicity in dogs treated with AR-H047108, an imidazopyridine proton pump inhibitor. Toxicol Pathol 2008;36:727-737.

24. Campbell CA, Gaskin PJ, Darton J, Chiu P, Lee K, McLean PG. Validation of a conscious rat model for the discovery of novel agents that inhibit gastric acid secretion. Eur J Pharmacol 2008;589:260-263.

25. Abelö A, Andersson M, Holmberg AA, Karlsson MO. Application of a combined effect compartment and binding model for gastric acid inhibition of AR-HO47108: a potassium competitive acid blocker, and its active metabolite AR-HO47116 in the dog. Eur J Pharm Sci 2006;29:91-101.

26. Simon WA, Herrmann M, Klein T, et al. Soraprazan: setting new standards in inhibition of gastric acid secretion. J Pharmacol Exp Ther 2007;321:866-874.

27. Kahrilas PJ, Dent J, Lauritsen K, et al. A randomized, comparative study of three doses of AZD0865 and esomeprazole for healing of reflux esophagitis. Clin Gastroenterol Hepatol 2007;5:1385-1391.

28. Dent J, Kahrilas PJ, Hatlebakk J, et al. A randomized, comparative trial of a potassium-competitive acid blocker (AZD0865) and esomeprazole for the treatment of patients with nonerosive reflux disease. Am J Gastroenterol 2008;103:20-26.

29. Kim HK, Park SH, Cheung DY, et al. Clinical trial: inhibitory effect of 
revaprazan on gastric acid secretion in healthy male subjects. J Gastroenterol Hepatol 2010;25:1618-1625.

30. Yi S, Lee H, Jang SB, et al. A novel $\mathrm{K}^{+}$competitive acid blocker, YH4808, sustains inhibition of gastric acid secretion with a faster onset than esomeprazole: randomised clinical study in healthy volunteers. Aliment Pharmacol Ther 2017;46:337-346.

31. Oh J, Lee S, Moon SJ, Lee SC, Lee A, Jang IJ. Pharmacokinetics, pharmacodynamics and tolerability of DWP14012, a novel acid pump antagonist, in healthy subjects. Gastroenterology 2017;152:S464.

32. Li CY, Su M, Yan YY, et al. KFP-H008 blocks gastric acid secretion through inhibiting $\mathrm{H}^{+}-\mathrm{K}^{+}$-ATPase. Eur J Pharmacol 2017;810:112119.

33. Takahashi N, Take Y. Tegoprazan, a novel potassium-competitive acid blocker to control gastric acid secretion and motility. J Pharmacol Exp Ther 2018;364:275-286.

34. Kondo M, Kawamoto M, Hasuoka A, Kajino M, Inatomi N, Tarui N. High-throughput screening of potassium-competitive acid blockers. J Biomol Screen 2012;17:177-182.

35. Arikawa $\mathrm{Y}$, Nishida H, Kurasawa O, et al. Discovery of a novel pyrrole derivative 1-[5-(2-fluorophenyl)-1-(pyridin-3-ylsulfonyl)-1H-pyrrol3-yl]-N-methylmethanamine fumarate (TAK-438) as a potassiumcompetitive acid blocker (P-CAB). J Med Chem 2012;55:4446-4456.

36. Shin JM, Inatomi N, Munson $\mathrm{K}$, et al. Characterization of a novel potassium-competitive acid blocker of the gastric H,K-ATPase, 1-[5-(2-fluorophenyl)-1-(pyridin-3-ylsulfonyl)- $1 \mathrm{H}$-pyrrol-3-yl]-Nmethylmethanamin e monofumarate (TAK-438). J Pharmacol Exp Ther 2011;339:412-420.

37. Matsukawa J, Hori Y, Nishida H, Kajino M, Inatomi N. A comparative study on the modes of action of TAK-438, a novel potassium-competitive acid blocker, and lansoprazole in primary cultured rabbit gastric glands. Biochem Pharmacol 2011;81:1145-1151.

38. Scott DR, Munson KB, Marcus EA, Lambrecht NW, Sachs G. The binding selectivity of vonoprazan (TAK-438) to the gastric $\mathrm{H}^{+}, \mathrm{K}^{+}$ATPase. Aliment Pharmacol Ther 2015;42:1315-1326.

39. Inatomi N, Matsukawa J, Sakurai Y, Otake K. Potassium-competitive acid blockers: advanced therapeutic option for acid-related diseases. Pharmacol Ther 2016;168:12-22.

40. Matsukawa J, Kogame A, Tagawa Y, Inatomi N. Radiographic localization study of a ovel potassium-competitive acid blocker, vonoprazan, in the rat gastric mucosa. Dig Dis Sci 2016;61:1888-1894.

41. Hori Y, Imanishi A, Matsukawa J, et al. 1-[5-(2-Fluorophenyl)1-(pyridin-3-ylsulfonyl)-1H-pyrrol-3-yl]-N-methylmethanamine monofumarate (TAK-438), a novel and potent potassium-competitive acid blocker for the treatment of acid-related diseases. J Pharmacol Exp Ther 2010;335:231-238.

42. Sostek MB, Chen Y, Andersson T. Effect of timing of dosing in relation to food intake on the pharmacokinetics of esomeprazole. Br J Clin Pharmacol 2007;64:386-390.

43. Echizen H. The first-in-class potassium-competitive acid blocker, vonoprazan fumarate: pharmacokinetic and pharmacodynamic considerations. Clin Pharmacokinet 2016;55:409-418.

44. Sugano K. Vonoprazan fumarate, a novel potassium-competitive acid blocker, in the management of gastroesophageal reflux disease: safety and clinical evidence to date. Therap Adv Gastroenterol 2018;11:1756283X17745776.

45. Sakurai Y, Nishimura A, Kennedy G, et al. Safety, tolerability, pharmacokinetics, and pharmacodynamics of single rising TAK-438 (vonoprazan) doses in healthy male Japanese/non-Japanese subjects. Clin Transl Gastroenterol 2015;6:e94.

46. Jenkins H, Sakurai Y, Nishimura A, et al. Randomised clinical trial: safety, tolerability, pharmacokinetics and pharmacodynamics of repeated doses of TAK-438 (vonoprazan), a novel potassium-competitive acid blocker, in healthy male subjects. Aliment Pharmacol Ther 2015;41:636648.

47. Shin JM, Kim N. Pharmacokinetics and pharmacodynamics of the proton pump inhibitors. J Neurogastroenterol Motil 2013;19:25-35.

48. Sakurai Y, Mori Y, Okamoto H, et al. Acid-inhibitory effects of vonoprazan $20 \mathrm{mg}$ compared with esomeprazole $20 \mathrm{mg}$ or rabeprazole $10 \mathrm{mg}$ in healthy adult male subjects--a randomised open-label cross-over study. Aliment Pharmacol Ther 2015;42:719-730.

49. Ashida K, Sakurai Y, Nishimura A, et al. Randomised clinical trial: a dose-ranging study of vonoprazan, a novel potassium-competitive acid blocker, vs. lansoprazole for the treatment of erosive oesophagitis. Aliment Pharmacol Ther 2015;42:685-695.

50. Jenkins H, Jenkins R, Patat A. Effect of multiple oral doses of the potent CYP3A4 inhibitor clarithromycin on the pharmacokinetics of a single oral dose of vonoprazan: a phase I, open-label, sequential design study. Clin Drug Investig 2017;37:311-316.

51. Williams MP, Sercombe J, Hamilton MI, Pounder RE. A placebocontrolled trial to assess the effects of 8 days of dosing with rabeprazole versus omeprazole on 24-h intragastric acidity and plasma gastrin concentrations in young healthy male subjects. Aliment Pharmacol Ther 1998;12:1079-1089.

52. Hori Y, Matsukawa J, Takeuchi T, Nishida H, Kajino M, Inatomi N. A study comparing the antisecretory effect of TAK-438, a novel potassium-competitive acid blocker, with lansoprazole in animals. J Pharmacol Exp Ther 2011;337:797-804

53. Kagami T, Sahara S, Ichikawa H, et al. Potent acid inhibition by vonoprazan in comparison with esomeprazole, with reference to CYP2C19 genotype. Aliment Pharmacol Ther 2016;43:1048-1059.

54. Astruc B, Jenkins H, Jenkins R. Effect of therapeutic and supratherapeutic doses of vonoprazan on the QT/QTc interval in a phase I randomized study in healthy subjects. Clin Transl Sci 2017;10:208-216.

55. Sachs G, Meyer-Rosberg K, Scott DR, Melchers K. Acid, protons and Helicobacter pylori. Yale J Biol Med 1996;69:301-316.

56. Sugimoto M, Furuta T, Shirai N, et al. Evidence that the degree and duration of acid suppression are related to Helicobacter pylori eradication by triple therapy. Helicobacter 2007;12:317-323.

57. Graham DY, Fischbach L. Helicobacter pylori treatment in the era of increasing antibiotic resistance. Gut 2010;59:1143-1153.

58. Murakami K, Furuta T, Ando T, et al. Multi-center randomized controlled study to establish the standard third-line regimen for Helicobacter pylori eradication in Japan. J Gastroenterol 2013;48:1128-1135.

59. Murakami K, Sakurai Y, Shïno M, Funao N, Nishimura A, Asaka M. 
Vonoprazan, a novel potassium-competitive acid blocker, as a component of first-line and second-line triple therapy for Helicobacter pylori eradication: a phase III, randomised, double-blind study. Gut 2016;65:14391446.

60. Jung YS, Kim EH, Park CH. Systematic review with meta-analysis: the efficacy of vonoprazan-based triple therapy on Helicobacter pylori eradication. Aliment Pharmacol Ther 2017;46:106-114.

61. Maruyama M, Tanaka N, Kubota D, et al. Vonoprazan-based regimen is more useful than PPI-based one as a first-line Helicobacter pylori eradication: a randomized controlled trial. Can J Gastroenterol Hepatol 2017;2017:4385161.

62. Sue S, Ogushi M, Arima I, et al. Vonoprazan- vs proton-pump inhibitor-based first-line 7-day triple therapy for clarithromycin-susceptible Helicobacter pylori: a multicenter, prospective, randomized trial. Helicobacter 2018;23:e12456.

63. Matsumoto H, Shiotani A, Katsumata R, et al. Helicobacter pylori eradication with proton pump inhibitors or potassium-competitive acid blockers: the effect of clarithromycin resistance. Dig Dis Sci 2016;61:3215-3220.

64. Noda H, Noguchi S, Yoshimine T, et al. A novel potassium-competitive acid blocker improves the efficacy of clarithromycin-containing 7-day triple therapy against Helicobacter pylori. J Gastrointestin Liver Dis 2016;25:283-288.

65. Mascellino MT, Porowska B, De Angelis M, Oliva A. Antibiotic susceptibility, heteroresistance, and updated treatment strategies in Helicobacter pylori infection. Drug Des Devel Ther 2017;11:2209-2220.

66. Graham DY, Shiotani A. New concepts of resistance in the treatment of Helicobacter pylori infections. Nat Clin Pract Gastroenterol Hepatol 2008;5:321-331.

67. Furuta T, Graham DY. Pharmacologic aspects of eradication therapy for Helicobacter pylori infection. Gastroenterol Clin North Am 2010; 39:465-480.

68. UMIN-CRT Clinical Trial. Comparison of dual amoxicillin/ vonoprazan therapy and triple vonoprazan/amoxicillin/clarithromycin or metronidazole therapy for $H$. pylori eradication. Available from URL: https://upload.umin.ac.jp/cgi-open-bin/ctr_e/ctr_view. cgi? recptno =R000026374 (accessed 5 May 2018).

69. Nishizawa T, Suzuki H, Fujimoto A, et al. Effects of patient age and choice of antisecretory agent on success of eradication therapy for Helicobacter pylori infection. J Clin Biochem Nutr 2017;60:208-210.

70. Sakurai Y, Shiino M, Okamoto H, Nishimura A, Nakamura K, Hasegawa S. Pharmacokinetics and safety of triple therapy with vonoprazan, amoxicillin, and clarithromycin or metronidazole: a phase 1, ppen-label, randomized, crossover study. Adv Ther 2016;33:1519-1535.

71. Fukuda D, Akazawa Y, Takeshima F, Nakao K, Fukuda Y. Safety and efficacy of vonoprazan-based triple therapy against Helicobacter pylori infection: a single-center experience with 1118 patients. Therap Adv Gastroenterol 2016;9:747-748.

72. Katayama Y, Toyoda K, Kusano Y, et al. Efficacy of vonoprazan-based second-line Helicobacter pylori eradication therapy in patients for whom vonoprazan-based first-line treatment failed. Gut 2017;66:752-753.

73. Inaba T, Iwamuro M, Toyokawa T, Okada H. Letter: promising results of Helicobacter pylori eradication with vonoprazan-based triple therapy after failure of proton pump inhibitor-based triple therapy. Aliment Pharmacol Ther 2016;43:179-180.

74. Kawashima K, Ishihara S, Kinoshita Y. Successful eradication of Helicobacter pylori infection with vonoprazan-based triple therapy after failure of PPI-based triple therapy. Dig Liver Dis 2016;48:688-689.

75. Kim JI, Park SH, Kim JK, Chung IS, Chung KW, Sun HS. The effects of nocturnal acid breakthrough on Helicobacter pylori eradication. Helicobacter 2002;7:331-336.

76. Takimoto M, Tomita T, Yamasaki T, et al. Effect of vonoprazan, a potassium-competitive acid blocker, on the ${ }^{13} \mathrm{C}$-urea breath test in Helicobacter pylori-positive patients. Dig Dis Sci 2017;62:739-745.

77. Rektorschek M, Weeks D, Sachs G, Melchers K. Influence of $\mathrm{pH}$ on metabolism and urease activity of Helicobacter pylori. Gastroenterology 1998;115:628-641.

78. Scott DR, Marcus EA, Weeks DL, Sachs G. Mechanisms of acid resistance due to the urease system of Helicobacter pylori. Gastroenterology 2002;123:187-195.

79. Dent J, El-Serag HB, Wallander MA, Johansson S. Epidemiology of gastro-oesophageal reflux disease: a systematic review. Gut 2005;54:710717.

80. El-Serag HB, Sweet S, Winchester CC, Dent J. Update on the epidemiology of gastro-oesophageal reflux disease: a systematic review. Gut 2014;63:871-880.

81. Altomare A, Guarino MP, Cocca S, Emerenziani S, Cicala M. Gastroesophageal reflux disease: update on inflammation and symptom perception. World J Gastroenterol 2013;19:6523-6528.

82. Miwa H, Takeshima T, Iwasaki K, Hiroi S. Medical cost, incidence rate, and treatment status of gastroesophageal reflux disease in Japan: analysis of claims data. J Med Econ 2016;19:1049-1055.

83. Iwakiri K, Kinoshita Y, Habu Y, et al. Evidence-based clinical practice guidelines for gastroesophageal reflux disease 2015. J Gastroenterol 2016;51:751-767.

84. Oshima T, Miwa H. Gastrointestinal mucosal barrier function and diseases. J Gastroenterol 2016;51:768-778.

85. Shan J, Oshima T, Muto T, et al. Epithelial-derived nuclear IL-33 aggravates inflammation in the pathogenesis of reflux esophagitis. J Gastroenterol 2015;50:414-423.

86. Hunt RH. Importance of $\mathrm{pH}$ control in the management of GERD. Arch Intern Med 1999;159:649-657.

87. Shaker R, Castell DO, Schoenfeld PS, Spechler SJ. Nighttime heartburn is an under-appreciated clinical problem that impacts sleep and daytime function: the results of a gallup survey conducted on behalf of the american gastroenterological association. Am J Gastroenterol 2003;98:1487-1493.

88. Farup C, Kleinman L, Sloan S, et al. The impact of nocturnal symptoms associated with gastroesophageal reflux disease on health-related quality of life. Arch Intern Med 2001;161:45-52.

89. Kinoshita Y, Hongo M. Efficacy of twice-daily rabeprazole for reflux esophagitis patients refractory to standard once-daily administration of PPI: the Japan-based TWICE study. Am J Gastroenterol 2012;107:522-530. 
90. Chey WD, Mody RR, Izat E. Patient and physician satisfaction with proton pump inhibitors (PPIs): are there opportunities for improvement? Dig Dis Sci 2010;5 5:3415-3422.

91. Ashida K, Sakurai Y, Hori T, et al. Randomised clinical trial: vonoprazan, a novel potassium-competitive acid blocker, vs. lansoprazole for the healing of erosive oesophagitis. Aliment Pharmacol Ther 2016;43:240251.

92. Hoshino S, Kawami N, Takenouchi N, et al. Efficacy of vonoprazan for proton pump inhibitor-resistant reflux esophagitis. Digestion 2017;95:156-161.

93. Iwakiri K, Sakurai Y, Shiino M, et al. A randomized, double-blind study to evaluate the acid-inhibitory effect of vonoprazan (20 $\mathrm{mg}$ and $40 \mathrm{mg}$ ) in patients with proton-pump inhibitor-resistant erosive esophagitis. Therap Adv Gastroenterol 2017;10:439-451.

94. Miwa H, Uedo N, Watari J, et al. Randomised clinical trial: efficacy and safety of vonoprazan vs. lansoprazole in patients with gastric or duodenal ulcers - results from two phase 3, non-inferiority randomised controlled trials. Aliment Pharmacol Ther 2017;45:240-252.

95. Satoh K, Yoshino J, Akamatsu T, et al. Evidence-based clinical practice guidelines for peptic ulcer disease 2015. J Gastroenterol 2016;51:177194.

96. Gabriel SE, Jaakkimainen L, Bombardier C. Risk for serious gastrointestinal complications related to use of nonsteroidal anti-inflammatory drugs. A meta-analysis. Ann Intern Med 1991;115:787-796.

97. García Rodríguez LA, Jick H. Risk of upper gastrointestinal bleeding and perforation associated with individual non-steroidal anti-inflammatory drugs. Lancet 1994;343:769-772.

98. Huang JQ, Sridhar S, Hunt RH. Role of Helicobacter pylori infection and non-steroidal anti-inflammatory drugs in peptic-ulcer disease: a meta-analysis. Lancet 2002;359:14-22.

99. Sakamoto C, Sugano K, Ota S, et al. Case-control study on the association of upper gastrointestinal bleeding and nonsteroidal anti-inflammatory drugs in Japan. Eur J Clin Pharmacol 2006;62:765-772.

100. Andrew R, Derry S, Taylor RS, Straube S, Phillips CJ. The costs and consequences of adequately managed chronic non-cancer pain and chronic neuropathic pain. Pain Pract 2014;14:79-94.

101. Moore RA, Derry S, Simon LS, Emery P. Nonsteroidal anti-inflammatory drugs, gastroprotection, and benefit-risk. Pain Pract 2014;14:378395.

102. Brown TJ, Hooper L, Elliott RA, et al. A comparison of the costeffectiveness of five strategies for the prevention of non-steroidal antiinflammatory drug-induced gastrointestinal toxicity: a systematic review with economic modelling. Health Technol Assess 2006;10:iii-iv, xi-xiii, $1-183$.

103. Sugano K, Kinoshita Y, Miwa H, Takeuchi T. Randomised clinical trial: esomeprazole for the prevention of nonsteroidal anti-inflammatory drug-related peptic ulcers in Japanese patients. Aliment Pharmacol Ther 2012;36:115-125.

104. Ivey KJ. Mechanisms of nonsteroidal anti-inflammatory drug-induced gastric damage. Actions of therapeutic agents. Am J Med 1988;84:4148.

105. Scarpignato C, Hunt RH. Nonsteroidal antiinflammatory drug-related injury to the gastrointestinal tract: clinical picture, pathogenesis, and prevention. Gastroenterol Clin North Am 2010;39:433-464.

106. Sakurai Y, Shïno M, Horii S, et al. Pharmacokinetic drug-drug interactions between vonoprazan and low-dose aspirin or nonsteroidal antiinflammatory drugs: a phase 2, open-label, study in healthy Japanese men. Clin Drug Investig 2017;37:39-49.

107. Mizokami Y, Oda K, Funao N, et al. Vonoprazan prevents ulcer recurrence during long-term NSAID therapy: randomised, lansoprazolecontrolled non-inferiority and single-blind extension study. Gut 2018;67:1042-1051.

108. Sugano K, Kontani T, Katsuo S, et al. Lansoprazole for secondary prevention of gastric or duodenal ulcers associated with long-term nonsteroidal anti-inflammatory drug (NSAID) therapy: results of a prospective, multicenter, double-blind, randomized, double-dummy, activecontrolled trial. J Gastroenterol 2012;47:540-552.

109. Sugano K, Kinoshita Y, Miwa H, Takeuchi T. Safety and efficacy of long-term esomeprazole $20 \mathrm{mg}$ in Japanese patients with a history of peptic ulcer receiving daily non-steroidal anti-inflammatory drugs. BMC Gastroenterol 2013;13:54.

110. Kawai T, Oda K, Funao N, et al. Vonoprazan prevents low-dose aspirin-associated ulcer recurrence: randomised phase 3 study. Gut 2018;67:1033-1041.

111. Sheen E, Triadafilopoulos G. Adverse effects of long-term proton pump inhibitor therapy. Dig Dis Sci 2011;56:931-950.

112. Johnson DA, Oldfield EC 4th. Reported side effects and complications of long-term proton pump inhibitor use: dissecting the evidence. Clin Gastroenterol Hepatol 2013;11:458-464.

113. Otsuka T, Sugimoto M, Inoue R, et al. Influence of potassium-competitive acid blocker on the gut microbiome of Helicobacter pylori-negative healthy individuals. Gut 2017;66:1723-1725.

114. Su T, Lai S, Lee A, He X, Chen S. Meta-analysis: proton pump inhibitors moderately increase the risk of small intestinal bacterial overgrowth. J Gastroenterol 2018;53:27-36.

115. Oshima T, Wu L, Li M, Fukui H, Watari J, Miwa H. Magnitude and direction of the association between Clostridium difficile infection and proton pump inhibitors in adults and pediatric patients: a systematic review and meta-analysis. J Gastroenterol 2018;53:84-94.

116. Vonoprazan study in patients with erosive esophagitis to evaluate longterm safety. Available from URL: https://clinicaltrials.gov/ct2/show/ NCT02679508 (assessed 5 May 2018). 